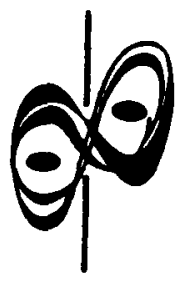

Acta Genet Med Gemellol 35: 167.178 (1986)

(C) 1986 by The Mendel Institute, Rome

Received 29 January 1986

Final 30 July 1986

\title{
Congenital Malformations in Twins: A Population Study
}

\section{Bengt Källén}

Department of Embryology, University of Lund, Sweden

\begin{abstract}
Malformations in twins were studied with the use of a Medical Birth Registry covering nearly all births in Sweden, 1973-1981. A total of 15,427 infants marked twins were identified and the malformation diagnoses were analyzed, comparing rates with the overall rates in the same data source. Problems in ascertainment and interpretation are discussed. No excess of neural tube defects was seen, but hydrocephaly was diagnosed more often in twins than in singletons. This can be partly, but not completely, explained by a higher rate of low-weight infants among twins. An excess was noticed in twins in the rates of cardiac defects, spine defects, gut atresias - notably esophageal and anal atresia and severe kidney malformations. These are components of the so-called VACTERL syndrome - the last component (limb reductions) being more common in twins than in singletons, though statistical significance was not reached. A relation between monozygotic twinning and this syndrome is tentatively suggested.
\end{abstract}

Key words: Congenital malformations, Twins, Population registry, Epidemiology

\section{INTRODUCTION}

The problem of malformations in twins has been the object of many studies. Twin pregnancies offer an opportunity to study the effect of genetic factors in the etiology of malformations, as twins in $\mathrm{MZ}$ and in $\mathrm{DZ}$ pairs can be compared, assuming that the main difference lies in the fact that the former share $100 \%$ and the latter only $50 \%$ of the genetic material. It should be remembered, however, that intrauterine environment may differ according to zygosity (eg, differences in vascular supply may affect the malformation rate) and also that $\mathrm{MZ}$ twinning in itself is a condition which may be related to other, perhaps specific groups of malformations. 


\section{Källén}

The main difficulty is to obtain materials large enough to study the relation between twinning and malformations. The largest study so far [4] - and the classical study in the field - was based on birth certificates for liveborn twins (born in 1961-66 in the USA) with one of a number of specified malformations mentioned and a sample of birth certificates from singletons. The material comprised approximately 4,000 malformed twins. The malformations under study were: facial clefts (divided into cleft lip, cleft lip and palate, and isolated cleft palate), anencephaly, spina bifida, hydrocephaly, congenital heart disease, positional foot defects, polydactyly, reduction deformities of limbs, and Down syndrome. The authors found a higher incidence of anencephaly, hydrocephaly, and congenital heart disease in like-sexed twins than in unlike-sexed twins or singletons, an increased incidence of positional foot defects in both types of twins compared to singletons, and a decreased incidence of Down syndrome in like-sexed twins. This study was thus restricted to some types of malformations and it can be expected that the restrictions to livebirths only and the use of birth certificates may have made the picture incomplete.

Others have tried to study this problem in defined populations. A study on approximately 57,000 consecutive births from Birmingham [7] also considered twinning and congenital malformations, but the very carefully followed material only contained 1,550 twins, 41 of which had a malformation. This figure is higher than expected but the difference does not reach statistical significance. The authors found a high rate of hydrocephaly (without other malformations) and - for like-sexed twins - of cardiac defects. The prospectively collected material from a U.S. collaborative study [8,9] comprised 56,244 births with 615 twin pairs. An increased rate of both major and minor malformations in $\mathrm{MZ}$ twins was found and the following malformations seemed to occur more often in twins than in singletons: encephalocele, orofacial clefts, tracheo-esophageal fistules, and malrotation of the gut.

In another study, malformations recorded in twins during 1969-1976 in the Metropolitan Atlanta Congenital Defects Program, a surveillance program run in Metropolitan Atlanta, were described [6]. Data were linked to vital records in Georgia and the study comprised 4,490 twins. A slightly different effect of twinning on malformation rate according to race was found. An increase in encephalocele rate was seen but not in other neural tube defect rates. Other malformations than neural tube defects were only studied in livebirths. An excess of hydrocephaly (only in blacks), patent ductus and tetralogy of Fallot, lung malformations, lower gastrointestinal defects, and omphalocele/gastroschisis was found. Excess malformations were mainly restricted to like-sexed twins. Pyloric stenosis and clubfoot were found more often in singletons than in twins.

A study in Scotland 1968-1979 [2] comprised 657 twin pairs. There was a statistically nonsignificant excess of malformations in $\mathrm{MZ}$ twins (types not specified).

A recent study on twinning and malformations used the Norwegian Medical Birth Register, 1967-1979 [13]. No definite increase in the general malformation rate in twins compared to singletons was found, but there were more central nervous system malformations and more cardiovascular defects registered in twins than in singletons. Malformations were studied only in broad categories, and total ascertainment appears low, as only $3 \%$ of all infants had a malformation diagnosis (including hernias, congenital hip subluxations and cardiac murmurs). This is only about $60 \%$ of what is registered in the similar Swedish registry and makes the study sensitive to ascertainment differences due to the phenomenon studied: twinning. 
Studies on twinning rates among patients with a specific type of malformation have also been published. An example is the Danish study on facial clefts [12] based on 71 twin pairs with cleft lip and/or cleft palate born in Denmark in 1941-1969. The cases were ascertained from a registry of persons with facial clefts who survived to the age of operation; stillbirths and early postnatal deaths are thus excluded. No increased rate of facial clefts was found in twins, but a concordance rate for cleft lip/palate which was much higher (but only approximately $50 \%$ ) in $\mathrm{MZ}$ than in $\mathrm{DZ}$ twins, though of a similar magnitude in $\mathrm{MZ}$ and $\mathrm{DZ}$ twins for isolated cleft palate.

The association of twinning and neural tube defects, especially anencephaly, has been studied repeatedly. In 109 Japanese twin pairs with anencephaly in at least one member and born in 1966-76 [5], the concordance rate was 8.3\%: among the 113 anencephalic twins, 60 were male. A population-based study was published [14], drawing material from Los Angeles County, USA, and Norway. For the latter material, the Norwegian Medical Birth Register was used for the period 1967-1979, while the Los Angeles data were from 1966 to 1972 . The total material represented 32,200 twins with a total of 50 neural tube defect infants. An overrepresentation of twinning was found in anencephaly and encephalocele but not in spina bifida; some heterogeneity, perhaps random, existes between the two materials.

\section{MATERIAL AND METHODS}

The present study is based on the Swedish Medical Birth Registry which started in 1973. During the years 1973-1981,896,953 infants were registered. For each infant, an abstract of the delivery record is stored, including diagnoses given to the mother during pregnancy or at delivery, and to the infant, including malformation diagnoses. All diagnoses are supplied from the delivery units and neonatal pediatric units as codes following the International Classification of Diseases, 8 th revision [15]. Obviously, this coding is not adequate for a detailed description of malformed infants. There is another registry in Sweden, The Registry of Congenital Malformations, which has a higher quality of diagnosis, especially for multimalformed infants, and information from that registry was also used.

A total of 15,427 infants were marked as twins but 87 of them were without a cotwin, leaving 7,670 pairs. These could be paired (using the mother's identification number, the date of birth and the time of birth) into 2,774 M-M, 2,776 F-F and 2,112 M-F pairs. In eight pairs, the sex was known only for one of the twin $(4 \mathrm{M}, 4 \mathrm{~F})$. The 87 cases of missing cotwins can have various explanations. In a few instances, a twin pair is born before the end of the 28th week with one twin liveborn and the other stillborn: then, only one twin is registered as an infant and enters the Medical Birth Registry, while the stillborn twin is registered as an abortion. Ten of the "single twins" were born before the end of the 28th week. Another possibility is that the primary marking as a twin was wrong: by comparison with the official vital statistics, this was found in 12 instances, but for some of the "single twins" identification numbers were wrong and a record-linkage could not be made. Finally, records for one twin may have disappeared. An effort is made to supplement defects in the registry, but some primary records have disappeared and cannot be retrieved.

For each one of the malformation types recorded, the number of twins with that 


\section{Källén}

malformation, among the 15,427 twins, was counted and compared with the expected number, calculated from the incidence of that malformation diagnosis among all births registered.

The next step in the analysis was restricted to the complete pairs. For each malformed twin, a main or leading diagnosis was settled if more than one malformation diagnosis was present: infants who had many specified severe malformations or were coded as "multimalformed" were put into a separate group, multimalformed.

\section{RESULTS}

Among twins belonging to M-M pairs, $314(5.7 \%)$ had at least one malformation diagnosis; among those belonging to F.F pairs, $267(4.8 \%)$ had such a diagnosis. In the unlike-sexed pairs, 211 twins $(141 \mathrm{M}, 70 \mathrm{~F})$ had at least one malformation diagnosis $(5.0 \%: 6.7 \%$ for males, $3.3 \%$ for females). The malformation rate in males is thus slightly higher in those belonging to unlike-sexed pairs and the opposite is true for females. Assuming equal numbers of like-sexed and unlike-sexed DZ pairs and an equal malformation rate in DZ twins irrespective of $\mathrm{DZ}$ pair type, the malformation rate can be estimated as 5.4 in $\mathrm{MZ}$ and 5.0 in DZ twins. This slight difference is not statistically significant but is in the same direction as that reported previously [eg, 2,14].

Both twins had malformation diagnoses in 103 pairs. The expected number of such pairs, assuming that the presence of a malformation in one twin is independent of that in the cotwin, is 41.7 and there is thus a surplus of approximately 60 pairs with both twins malformed. Among the 103 pairs, 20 were unlike-sexed and 83 like-sexed which gives an estimated monozygosity rate of $61 \%$, which is significantly higher than that estimated among all twins (44.9\%, Hardy-Weinberg law). In the 103 pairs, 80 are concordant with respect to malformations: this can partly be due to genetic and environmental similarities for the twins but also to an increased ascertainment of a malformation in a twin if the cotwin has a malformation.

The Table lists the main malformation diagnoses recorded giving, for each one, the number found among all 15,427 twins studied and the expected number, calculated from the incidence of that diagnosis in the registry (including singletons). The number of twins with each diagnosis as the main one is also given by pair type. For unlike-sexed pairs, the distribution of the diagnoses in males and females is also given. The number of pairs where both twins are malformed is tabulated, and also the number of pairs with both twins having diagnoses belonging to the same diagnostic group (eg, cardiac defect, not necessarily exactly the same defect). Finally, distribution by birth order of twins is also given.

The Figure shows the ratios between found and expected numbers for the most common major and minor malformations.

In this material, neural tube defects were not more frequent in twins than expected. A total of 11 diagnoses were given and 11.7 were expected. Among the multimalformed infants (coded 759.9), one had a neural tube defect according to the Registry of Congenital Malformations. One infant has two neural tube defects, leaving 11 infants -6 anencephalics and 5 with spina bifida, including the multimalformed infant. One concordant pair of anencephalics was included, both infants also having cleft palate.

Hydrocephaly occurred in 23 twins and the expected number is only 5.1. In 21 . 
Table. Malformations registered in 15,427 twins compared to expected number from all births. For each twin, a leading malformation was selected or, when this was not possible, the twin was classified as multimalformed. Sex distribution, concordance and birth order are also considered.

\begin{tabular}{|c|c|c|c|c|c|c|c|c|c|c|c|c|}
\hline \multirow{2}{*}{ Diagnosis } & \multirow{2}{*}{\multicolumn{2}{|c|}{$\begin{array}{l}\text { No. of twins } \\
\text { Found Exp. }\end{array}$}} & \multirow{2}{*}{$\begin{array}{l}\text { Main } \\
\text { diagn. }\end{array}$} & \multicolumn{3}{|c|}{$\begin{array}{c}\text { Sex of } \\
\text { twin pair }\end{array}$} & \multicolumn{2}{|c|}{$\begin{array}{l}\text { Sex in } \\
\text { MF pair }\end{array}$} & \multicolumn{2}{|c|}{$\begin{array}{c}\text { Both } \\
\text { twins malf. }\end{array}$} & \multicolumn{2}{|c|}{$\begin{array}{l}\text { Birth } \\
\text { order }\end{array}$} \\
\hline & & & & $\mathrm{MM}$ & $\mathrm{FF}$ & MF & $\mathbf{M}$ & $F$ & All & Conc: & I & II \\
\hline Neural tube defect & 11 & 11.7 & 10 & 6 & 1 & 3 & 3 & 0 & 3 & 2 & 6 & 4 \\
\hline Hydrocephaly & 23 & 5.1 & 21 & 13 & 6 & 2 & 1 & 1 & 8 & 4 & 9 & 12 \\
\hline Other CNS mall. & 6 & 5.2 & 5 & 2 & & 3 & 2 & 1 & 2 & 2 & 3 & 2 \\
\hline Eye malf. & 3 & 2.6 & 2 & & & 1 & 1 & & & & 2 & 1 \\
\hline Severe ear malf. & 1 & 2.0 & 1 & & 1 & & & & & & 1 & \\
\hline Minor ear malf. & 37 & 46.2 & 36 & 15 & 10 & 11 & 7 & $\mathcal{4}$ & 8 & 4 & 14 & 22 \\
\hline Heart/vessel malf. & 269 & 111.1 & 242 & 85 & 101 & 55 & 24 & 31 & 65 & 56 & 126 & 115 \\
\hline among them: suspected & 51 & 21.2 & 49 & 17 & 24 & 8 & 3 & 5 & 14 & 8 & 49 & 45 \\
\hline 2 umbilical vessels & 21 & 10.6 & 18 & 5 & 9 & 4 & 2 & 2 & 4 & 2 & 3 & 15 \\
\hline Respiratory tract malf. & 7 & 10.5 & 4 & 1 & 3 & & & & & & 3 & 1 \\
\hline Facial clefts & 27 & 26.9 & 23 & 10 & 6 & 7 & 4 & 3 & 6 & 4 & 14 & 9 \\
\hline Upper alim. tract malf. & 4 & 3.0 & 2 & 1 & 1 & & & & & & 1 & 1 \\
\hline Esophageal atresia & 10 & 4.3 & 8 & 3 & 5 & & & & 2 & 2 & 4 & 4 \\
\hline Small gut atresia & 4 & 3.0 & 4 & 1 & 3 & & & & & & 2 & 2 \\
\hline Anal atresia & 9 & 4.7 & 7 & 4 & 1 & 1 & 1 & & 5 & 4 & 4 & 2 \\
\hline all atresias: & 24 & 12.0 & 19 & 8 & 9 & 1 & 1 & & 7 & 6 & 10 & 8 \\
\hline Other gut malf. & 4 & 7.5 & 4 & 3 & & 1 & & 1 & 1 & & 1 & 1 \\
\hline Intersex & 3 & 0.3 & 3 & 1 & 2 & & & & 2 & 2 & 1 & 2 \\
\hline Retentio testis & 57 & 57.7 & 55 & 31 & & 24 & 24 & & 7 & 4 & 34 & 21 \\
\hline Hypospadias & 22 & 28.9 & 22 & 18 & & 3 & 3 & & 5 & 4 & 11 & 10 \\
\hline Hydrocele testis & 59 & 83.7 & 57 & 38 & & 19 & 19 & & 11 & 6 & 35 & 22 \\
\hline Kidney a/hypoplasia & 7 & 2.8 & 7 & 3 & 2 & 2 & 1 & 1 & 2 & 2 & 4 & 3 \\
\hline Polycystic kidiucy & I & 2.2 & 1 & 1 & & & & & & & 1 & \\
\hline Hydronephrosis & 3 & 1.7 & 3 & & I & 2 & 1 & 1 & 2 & 2 & 2 & 1 \\
\hline Ureter malf. & 3 & 0.9 & 2 & 2 & & & & & & & 1 & 1 \\
\hline Exstrophia vesicae & 1 & 0.4 & 1 & & 1 & & & & & & & 1 \\
\hline Other urinary malf. & 4 & 3.5 & 0 & & & & & & & & & \\
\hline Pósitional foot defects & 74 & 74.4 & 68 & 19 & 28 & 21 & 16 & 5 & 13 & 10 & 44 & 24 \\
\hline Połydactyly & 14 & 14.3 & 11 & 2 & 5 & 4 & 4 & & 5 & 4 & 7 & 4 \\
\hline Syndactyly & 16 & 17.8 & 14 & 6 & 5 & 3 & 3 & & 8 & 8 & 7 & 4 \\
\hline Limb reduction & 10 & 7.2 & 9 & 2 & 3 & 4 & 4 & & & & 4 & 5 \\
\hline Other limb malt. & 8 & 0.6 & 3 & & 3 & & & & & & 2 & 1 \\
\hline Cong. hip (sub) lux. & 104 & 199.2 & 86 & 16 & 47 & 23 & 8 & 15 & 24 & 20 & 43 & 43 \\
\hline Craniostenosis & 2 & 1.5 & 2 & 1 & 1 & & & & & & & 2 \\
\hline Spine malf. & 6 & 1.7 & 2 & 1 & & 1 & 1 & & & & 1 & 1 \\
\hline Other skeletal malf. & 5 & 6.4 & 2 & & 2 & & & & 1 & & 1 & 1 \\
\hline Omplaalocele/diaphragmi. hernia & 2 & 5.5 & 2 & & 1 & 1 & 1 & & & & & 2 \\
\hline Nevis & 7 & 24.4 & 7 & 3 & 2 & 2 & 2 & & & & 3 & 4 \\
\hline Unspec. skin malf. & 3 & 4.2 & 3 & & & 3 & 3 & & & & 2 & 1 \\
\hline Various malformations & 3 & 2.6 & 0 & & & & & & & & & \\
\hline Situs inversus & 1 & 0.5 & 1 & & & 1 & 1 & & & & & 1 \\
\hline Down's syndrome & 10 & 16.8 & 10 & 4 & 1 & 5 & 3 & 2 & 1 & & 8 & 2 \\
\hline Multimalformed & - & - & 27 & 11 & 8 & 5 & 2 & 3 & 8 & 6 & 2 & 3 \\
\hline
\end{tabular}




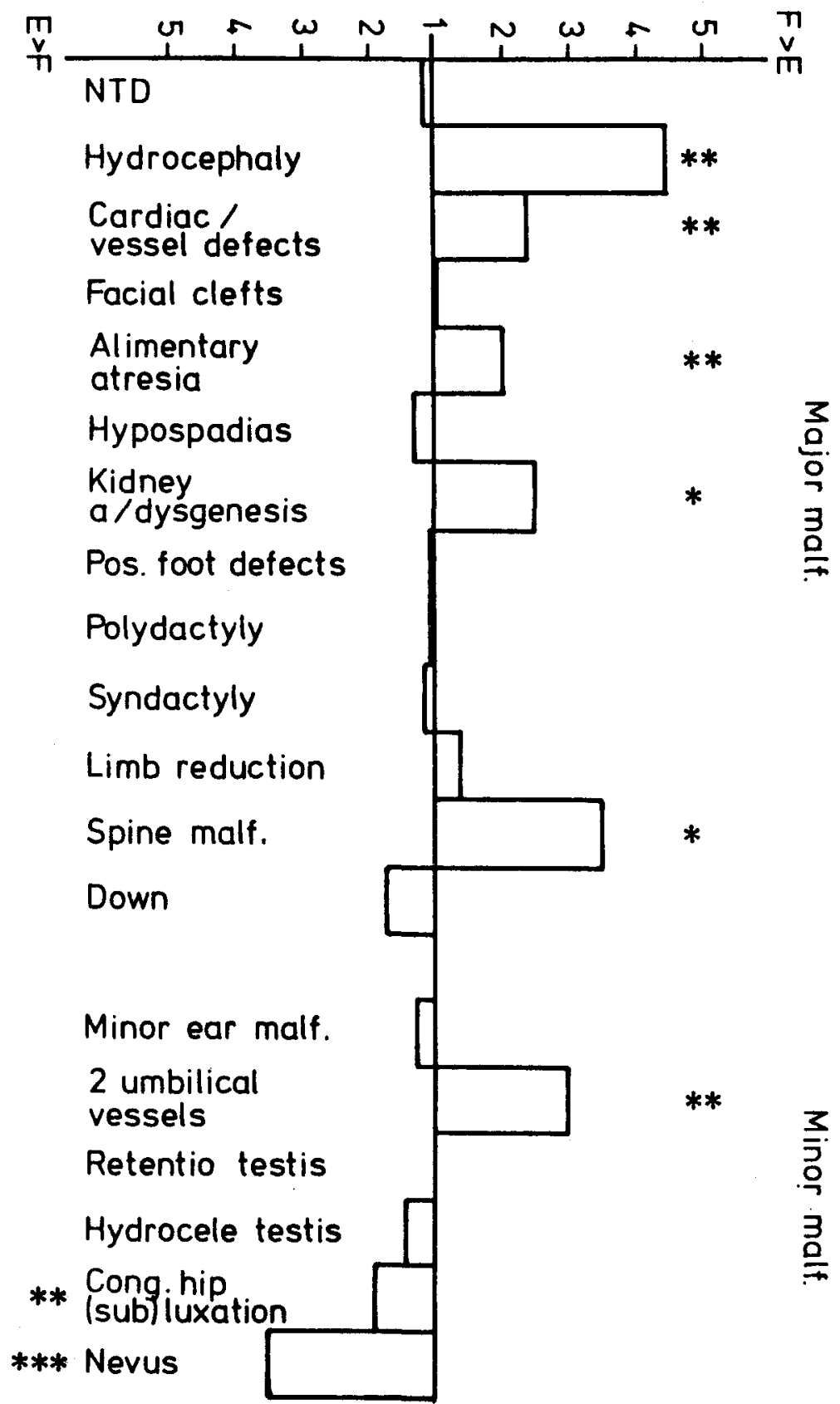

Figure: Diagram showing ratio between found number $(F)$ and expected number $(E)$ of some specified malformations in twins. If $\mathrm{F}>\mathrm{E}$, that is, the malformation is more common in twins than in singletons, the $\mathrm{F} / \mathrm{E}$ ratio is shown as a bar above the 1.0 line. Il $\mathrm{F}<\mathrm{E}$, that is, the malformation is less common in twins than in singletons, the $\mathrm{E} / \mathrm{F}$ ratio is shown as a bar below the 1.0 line. * marks $0.05>$ $>\mathrm{P}>0.01$, and ${ }^{* *} 0.01>\mathrm{P}>0.001$ (Poisson model). The malformations are divided into two groups: major and minor. 
hydrocephaly was the leading malformation. Of these, 19 belonged to like-sexed pairs, which is slightly more than expected (15.4), but this difference can of course be random.

Concordance was present in two pairs, both M-M. It should be noted that, in the Medical Birth Registry, hydrocephaly is recorded more often among low-birthweight than in fullterm infants. Among singleton births, 0.21 per 1,000 have hydrocephaly if birthweight is over $2,500 \mathrm{~g}$, and 2.29 per 1,000 if it is below $2,500 \mathrm{~g}$. The corresponding figures for twins are 0.79 and 1.97, respectively. Thus, among fullterm births, the rate is increased 3-4 times ( 7 found, 1.9 expected, $P<0.01$ ), while no difference is seen below $2,500 \mathrm{~g}$ ( 13 found, 15.1 expected). The high rate of hydrocephaly is thus mainly, though not totally, explainable by the prematurity of twins.

Cardiovascular defect diagnoses were significantly more frequent in twins than in singletons. The diagnostic quality of the Medical Birth Registry does not permit a comparison of various heart malformations. The frequency of like-sexed twins is increased (186 found, 175.2 expected), but this could be random. One category can be separated: suspected cardiac malformations. These behave similarly to the more definite diagnoses, which speaks against an over-recording of the conditions due to twinning. In the majority of cases, no specified cardiac diagnosis was available. In 23 infants, however, a diagnosis of VSD had been given, 3 had a transposition of the great vessels, 4 had a hypoplastic left heart syndrome, and another 16 had other specified defects (one-two of each kind).

The found and expected numbers of facial clefts were nearly identical and the same applied to the proportion of like-sexed twins (16 found, 16.6 expected). In two pairs, both twins had facial clefts; in one pair, both had cleft lip/palate; in the other, both had cleft palate. To this can be added the pair mentioned above, concordant for both anencephaly and cleft palate.

There was an increase in the rate of esophageal or gut atresias among twins. If all atresia diagnoses are regarded together, twice as many as expected are found. This is true for both esophageal and anal atresia, but numbers for each subgroup are small. There is a strong preponderance of like-sexed twins in this group. All 12 infants with esophageal or other gut atresias were like-sexed and so were 5 of the 6 pairs with known sexes and anal atresia. Thus, 17 among 18 pairs with gut atresia were like-sexed, which indicates an increase in the monozygosity rate $(\mathrm{P}<0.05)$.

Hypospadias occurred in twins slightly less often than expected but this may be random. Among the 22 twins recorded, 18 belonged to M-M pairs, two of which were concordant for hypospadias.

Kidney agenesis or severe dysgenesis occurred in 7 twins against 2.8 expected $(\mathrm{P}<$ $<0.05$ ). One pair was concordant for the kidney malformations, a F-F pair with one bilateral and one unilateral agenesis. Most probably, the latter infant had not been diagnosed in the newborn period but for the malformation in the cotwin.

Positional foot defects were not more frequent in twins than in singletons. Polydactyly and syndactyly have no increased frequency but the concordance rate is rather high: among 9 pairs with polydactyly, 2 were concordant; and among 10 pairs with syndactyly, 4 were concordant. All 6 concordant pairs were like-sexed.

Limb reductions occurred slightly more often than expected, but this could be random: 10 found, 7.2 expected. No pairs were concordant. Spine malformations occurred more frequently than expected but usually with other malformations which were regarded as the leading one. 


\section{Källén}

Down syndrome occurred less often than expected - but no correction for maternal age was made. As DZ twinning increases with age, the age factor should sooner increase the Down syndrome rate. There are fewer like-sexed pairs than expected and no concordant pairs. In one M-M pair, one twin had Down syndrome and the cotwin hydrocephaly.

Among minor malformations, no deviations from the expected number was seen for minor ear malformations like preauricular tags, for retentio testis or hydrocele testis. There was a significant increase in the rate of two umbilical vessels and a decrease in congenital (sub)luxation of the hip and in nevus.

It can be noted that the sex distribution in twins with a specific malformation sometimes differs from that known for singletons with that malformation. There is a male preponderance for neural tube defects $(10: 1)$ in contrast with the usual female preponderance (49.1\% males) in singletons. There is a female preponderance for cardiovascular defects ( $45.2 \%$ males) in contrast with the male preponderance seen in singletons ( $54.9 \%$ males) $\left(\chi_{1}^{2}=9.1, P<0.01\right)$. For the other types of malformations, sex distribution did not deviate in twins as compared to singletons (eg, female preponderance at congenital hip (sub)luxation).

There was no significant difference in distribution between first-born and secondborn twins for any malformation, with the possible exception of positional foot defects, more common in twin $\mathrm{I}(\mathrm{Bin}(68,0.50)=44$ gives $\mathrm{P}<0.05)$; but since many different malformations were studied, this may well be random.

\section{DISCUSSION}

The results illustrate some of the problems indicated in the Introduction, inherent in studies on the association between twinning and congenital malformations. In spite of the fact that the study is based on nearly one million births, numbers for specific malformations are so low that many of the findings can be random. We have also seen examples that illustrate the problem of differences in ascertainment when twinning is present. In one pair, both twins were registered as having kidney agenesis, but one had a unilateral agenesis which perhaps would have never been detected, had the cotwin not presented a bilateral renal agenesis. Differences in ascertainment may also have the opposite effect and the probability for a twin to have a malformation diagnosis may be reduced. This is probably of greatest significance for minor anomalies, the most obvious example being nevus. As only a limited number of diagnoses can be registered for each infant, the higher probability for a twin to have a clinically important condition (like idiopathic respiratory distress syndrome) will reduce the probability that a diagnosis of a minor defect like a nevus be included. This makes it difficult to evaluate the crude prevalence at birth of malformations in twins vs singletons and the slightly increased rate of malformations found in $\mathrm{MZ}$ twins may actually be an understatement.

Also, the fact that twins are usually born after a shorter gestational period than singletons may affect the probability of a malformation diagnosis - both a minor one, such as congenital (sub)luxation of the hip, and a major one, such as hydrocephaly - when the malformation or its clinical appearance is influenced by the gestational age of the infant. Another example is patent ductus arteriosus, which appears more often in premature than 
in fullterm infants and was also found to be more common in twins than in singletons as described previously [6]. Actually, 59 of the cardiovascular defects (as a leading diagnosis) consisted of patent ductus without further cardiac defect, but even disregarding these, the surplus of cardiac defects in twins is significant.

These considerations emphasize the need to study the problem of malformations and twinning using data of a high diagnostic quality and also as completely ascertained as possible. Conclusions based on crude malformation rates will be very uncertain.

\section{Neural Tube Defects}

We found no significant increase in neural tube defects among twins. This is at variance with most earlier studies. Hay and Wehrung [4] described a higher rate of anencephaly in like-sexed than in unlike-sexed twins or in singletons, but a similar rate of spina bifida in like-sexed twins and singletons and a lower rate in unlike-sexed twins. McKeown and Record [7] found no increase in neural tube defects among twins in their material. In neither of these studies fetal deaths were included. Windham et al [14], however, examined stillbirths and late fetal deaths (after the 16th or 20th week) and found a significant excess of neural tube defects in twins, especially anencephaly. Except for the inclusion of late fetal deaths, this data base is very similar to the present one and about twice its size. Windham et al found 50 infants with neural tube defects among 32,200 twins and we found 11 in 15,247 . This difference is of borderline statistical significance $(0.05>\mathrm{P}>0.01)$ and is most likely explainable by the inclusion of late fetal deaths in the former material. The rate of anencephaly among twins in the present material is 0.39 per 1,000 (population rate 0.23 ) and that of spina bifida is 0.32 (population rate 0.40 ), while the corresponding rates in Windham et al study were $0.78(0.48)$ and $0.56(0.50)$, respectively. These comparisons are further complicated by the fact that the low anencephaly rate in Sweden (especially during the last few years of the observation period) is due to some extent to prenatal diagnosis followed by selective abortion - and this procedure cannot be applied in the same way in twin pregnancies as in singletons. We had no infants with encephalocele among the twins studied: from the population rate one would expect only 1.3 . In Windham et al's study an excess of encephalocele among twins was found in Los Angeles - as also reported in other USA studies [6,8] - but not in Norway.

The sex distribution of infants with neural tube defect in our material also differs from that found by Windham et al. We had 9/10 males (+ one multimalformed male with spina bifida) which contrasts with the sex distribution in singletons with neural tube defects as well as with the finding of Windham et al who had less males than females (ratio 0.85 for all neural tube defects in twins, and 0.79 in singletons). Hay and Wehrung [4] found the same female preponderance in unlike-sexed twins as in singletons with neural tube defects, but found a preponderance of males in like-sexed twins. In a study on stillbirths and neonatal deaths [5], more male than female twins with anencephaly were found. Among 6 like-sexed twin pairs with at least one neural tube defect in our material, 5 were male. An explanation could be that female twin fetuses with neural tube defect die late in fetal life, after the 16th week, and were therefore included in the data of Windham et al [14] but not in our data or in the data of Hay and Wehrung [4], restricted to livebirths. 


\section{Källén}

\section{Hydrocephaly}

The excess of hydrocephaly in twins has been reported many times and is restricted to isolated hydrocephaly [7]. Hay and Wehrung [4] found some increase of the hydrocephaly rate in like-sexed vs unlike-sexed twins or singletons and found a low degree of concordance. Layde et al [6] found an increase only in black twins. Windham and Bjerkedal [13] mention a high rate in twins. We also have a high rate of hydrocephaly in twins, and mainly in like-sexed twins, with a rather high concordance rate ( $4 / 21$ belonged to concordant pairs). The explanation of these differences may lie in the data sources. Birth certificates contain information about malformations found at birth [4]. McKeown and Record [7] followed the infants for two weeks after birth and our data were collected during the stay of the infant at the delivery unit or in pediatric care directly following delivery. It is reasonable to assume that the latter two studies include hydrocephaly developing during the first week(s) of life, that is, also hydrocephaly resulting from delivery damage. We also have a markedly higher rate of hydrocephaly in low-birthweight than in fullterm singletons. Inclusion of hydrocephaly developing after birth would increase the rates in twins as the preterm rate in twins is higher than in singletons. This factor could explain much of the increased rate registered, but also among twins weighing above 2500 $\mathrm{g}$ more cases of hydrocephaly were found than in singletons of that weight. It can also be noted that the hydrocephaly rate in twins II was somewhat higher than in twins I (although the difference does not reach statistical significance).

\section{Cardiovascular Defects}

An increased rate of cardiac defects in like-sexed but not in unlike-sexed twins vs singletons has been described [4]. The rates registered were 3.4 per 10,000 births, which of course is a very low figure, explainable by the data source: birth certificates. The same finding was made in a study on British twins [1]. Also McKeown and Record [7] found an increase in cardiac defects among twins, but the relatively small material did not allow any definite conclusions. Layde et al [6] reported an increased rate of patent ductus and Fallot's tetrad in twins. Windham and Bjerkedal [13] found an increased rate of cardio. vascular defects in twins vs singletons, but the absolute rates are rather low $(2.41 / 1,000$ in singletons and 3.5/1,000 in twins, against $6.7 / 1,000$ in singletons and 14.1/1,000 in twins in our material, suspected cardiac defects included). Thus, we have a clearcut increase in cardiac defect diagnoses in twins vs singletons. We have a slight, but not significant increase of like-sexed pairs with cardiac defects and a high rate of concordance. Unfortunately, diagnostic quality of the registry does not permit a detailed study of the cardiac defects present. A detailed cardiac malformations registry was not available in Sweden before 1981 and, in order to study more closely the cardiac defects in the present material, one would have to go back to the original hospital records of each individual case.

\section{Facial Clefts}

We found no increase in facial clefting in twins vs singletons and no increase in like-sexed pairs. This agrees well with some previous findings [4] and with the study on Danish twins with facial clefts [12], but an increased rate of orofacial clefts in twins has been described [8]. Our material is much too small to study concordance for clefts, but in the three pairs where both twins had clefts, they were of the same type in the two cotwins. 


\section{Positional Foot Defects}

In contrast with Hay and Wehrung [4], we found no excess of positional foot defects in twins vs singletons. Again, this can be explained by differences in the data sources. It may be that slight defects, resulting from intrauterine crowding, are more easily recorded on birth certificates than as a final discharge diagnosis from the delivery ward or pediatric ward. That intrauterine factors may play a role also in our material is, however, indicated by the higher rate of the anomaly in twins I than in twins II. The diagnostic quality of the registry is not high enough to allow a detailed analysis of various types of positional foot defects, but 44 of the 68 "leading" diagnoses were coded as pes equinovarus. A higher rate of talipes in singletons than in twins has been described in one study [6].

\section{Some Other Malformations}

We found a significant excess of alimentary atresia - esophageal atresia, anal atresia and other gut atresia - in twins vs singletons and this was nearly exclusively restricted to likesexed twins: among 18 pairs of known sex, 17 were like-sexed. Furthermore, concordance was rather common (3/13 pairs). An excess of lower gastrointestinal defects [6] and of tracheo-esophageal fistules [8] has previously been described. Windham and Bjerkedal [13] even found the number of twins with respiratory tract or digestive system malformation to be slightly lower than expected, but did not analyze specific malformation types.

Severe kidney malformations were registered more often in twins than in singletons, especially kidney agenesis or dysgenesis. Limb reductions were also registered more often in twins than in singletons, but the difference was not significant. Hay and Wehrung [4] found no increase in reduction deformities in twins. We found a higher rate of spine deformities in twins than in singletons.

Down syndrome occurred less often in twins than in singletons, which agrees with previous observations [4]. There is, in our material, a complete lack of concordant pairs, and probably also of MZ pairs, as reflected by the distribution of like-sexed and unlikesexed pairs. This also agrees with the statements made in the literature that $M Z$ twins with Down syndrome are rare, probably as a result of embryonic or fetal death.

\section{Twinning and the VACTERL Syndrome: A Hypothesis}

We found an increased rate in twins of the following malformations: hydrocephaly, cardiac defects, alimentary tract atresias (notably esophageal and anal atresia), spine malformations, and (but not reaching statistical significance) limb reductions. The initials of these malformations, with the exception of hydrocephaly, are $\mathrm{V}$ (vertebral), $\mathrm{A}$ (anal), C (cardiac), TE (tracheoesophageal), R (renal) and L (limb), resulting in VACTERL, a much debated syndrome developing from the VATER syndrome [11]. The existence of the VACTERL syndrome as a true entity has been debated and it is often believed that these infants are part of a family of syndromes, comprising Potter syndrome, VACTERL, the syndrome of caudal regression, and perhaps the prune belly syndrome. All are probably the result of disturbances in the caudal axial mesoderm in early embryonic development. It is interesting that the malformations showing an increased rate in twins fall into this constellation and one can hypothesize that primitive streak anomalies resulting in $\mathrm{MZ}$ twinning can also affect axial mesoderm development with perhaps an increased risk for this group of malformations. It can also be noted that among the 27 twins with multiple malformations, at least 9 had malformations belonging to this category 


\section{Källén}

(and not counted above). Further studies on larger materials with a high diagnostic quality are needed to test this hypothesis. Similar ideas have been expressed previously in the literature $[3,10]$.

\section{CONCLUSIONS}

Some types of malformations occur more often in twins than in singletons, other types apparently do not. The risk increase is moderate and requires a large data base to be demonstrated. The changed risk for certain types of malformations (eg, hydrocephaly, patent ductus) may at least partly be secondary to preterm births; in other cases (notably, minor defects like nevus) it may be due to a changed ascertainment.

Certain major malformations do occur more often in twins than in singletons: most are part of the so-called VACTERL syndrome, thought to be the result of an early axial mesoderm damage which could be closely related to the process of twinning.

\section{REFERENCES}

1. Burn J, Corney G (1984): Congenital heart defects and twinning. Acta Genet Med Gemellol 33:61-69.

2. Corney G, MacGillivray I, Campbell DM, Thompson B, Little J (1983): Congenital anomalies in twins in Aberdeen and Northeast Scotland. Acta Genet Med Gemellol 32:31-35.

3. Greene C, Wilsoin A, Shapira E (1985): Prune belly syndrome and heart defect in one of monozygotic twins, following exposure to Tigan and Bendectin. Acta Genet Med Gemellol 34:101-104.

4. Hay S, Wehrung DA (1970): Congenital malformations in twins. Am J Hum Genet 22:662-678.

5. Imaizumi Y (1978): Concordance and discordance of anencephaly in 109 twin pairs in Japan. Jap J Hum Genet 23:389-393.

6. Layde PM, Erickson JD, Falek A, McCarthy BJ (1980): Congenital malformations in twins. Am J Hum Genet 32:69-78.

7. Mckeown T, Record RG (1960): Malformations in a population observed for five years after births. In Wolstenholme GEW, O'Connor CM (eds): Ciba Foundation Symposium on Congenital Malformations. London: J \& A Churchill Lts, pp 2-16.

8. Myrianthopoulos NC (1975): Congenital malformations in twins: epidemiologic survey. Birth Defects (Orig Art Ser) 11:1-39.

9. Myrianthopoulos NC (1976): Congenital malformations in twins. Acta Genet Med Gemellol 25: 331.335.

10. Nance WE (1981): Malformations unique to the twinning process. In Gedda L, Parisi P, Nance WE (eds): Twin Research 3. Part A: Twin Biology and Multiple Pregnancy. New York: Alan R Liss, pp 123-133.

11. Nora AH, Nora JJ (1975): A syndrome of multiple congenital anomalies associated with teratogenic exposure. Arch Environ Health 30:17-21.

12. Shields ED, Bixler D, Fogh-Andersen P (1979): Facial clefts in Danish twins. Cleft Palate J 16: $1 \cdot 6$.

13. Windham GC, Bjerkedal T (1984): Malformations in twins and their siblings, Norway, 1967 1979. Acta Genet Med Gemellol 33:87-95.

14. Windham GC, Bjerkedal T, Severe LE (1982): The association of twinning and neural tube defects: studies in Los Angeles, California, and Norway. Acta Genet Med Gemellol 31:165-172.

15. World Health Organization (1967): Manual of the International Statistical Classification of Diseases, Injuries, and Causes of Death. Geneva: WHO.

Correspondence: Professor Bengt Källén, Department of Embryology, Biskopsgatan 7, S-223 62 Lund, Sweden. 